\title{
Significant Moments in Improvisational Music Therapy:
}

\section{Composite Case Examples of Improvisation With Adults Diagnosed With Intellectual and Developmental Disabilities}

\author{
Katelyn Beebe ${ }^{1 \text { * }}$ \\ 1 Non-affiliated, USA \\ *katelyn.p.beebe@gmail.com \\ Received: 30 August 2020 Accepted: 21 September 2021 Published: 1 November 2021 \\ Editor: Susan Hadley Reviewer: Simon Gilbertson
}

\begin{abstract}
Four composite case examples are presented and discussed as they relate to emotional expression, significant moments in the therapeutic process, and communication using a variety of modalities in music therapy with adults diagnosed with intellectual and developmental disabilities. Building on therapeutic awareness through discussing musical elements, body movement and posture, countertransference, and interactional patterns, the implications of deep emotional connection and processing are approached using primarily nonverbal methods. Composite vignettes from the author's clinical work demonstrate awareness of these factors in the moment as they impacted the session, therapeutic relationship, and other professionals' understanding of music therapy in this population. Implications for emotional processing in clinical practice are presented as they relate to the concepts presented in this paper.
\end{abstract}

Keywords: improvisation, countertransference, emotional processing, intellectual disability, case example

\section{Introduction}

Improvisation in music therapy invites connection through a unifying experience that often involves the expression of some type of emotional content and is directed towards the growth of the client (Bruscia, 2014; Dillard, 2006; Graham, 2004; Seabrook, 2019; Strehlow \& Lindner, 2014). Improvisation creates a sacred space, the musical space, for exploration and relationship (Kenny, 2006). This space can hold safety, relationship, spontaneity, receptivity, and creative potential. By participating in the creative process, the client is actively creating and therefore embarking toward change. Novel and innovative communication can be met with enthusiasm and acceptance 
from the therapist in this space (Graham, 2004; Polen, 2013; Swaney, 2017; Swaney, 2020). Deep connections can be made within the safety and acceptance present within the therapeutic relationship and musical space.

Communication and connection are accomplished through body movement, facial expression, melody, rhythm, and a felt sense of being united in an experience (Graham, 2004; Swaney, 2020). The therapist then becomes attuned to many possible methods a client uses to engage in the therapeutic space by entering an expressive relationship through improvisation (Cameron, 2017; Swaney, 2020). For some individuals, verbal processing leads to inauthentic experiences or resistance even when verbal language is their primary form of communicating with others (Gavrielidou \& Odell-Miller, 2017; Polen, 2013). Improvisation can allow the therapist and client to engage in exploration and communication in a contained environment without the barriers that may come with verbal processing.

\section{Significant Therapeutic Moments}

Therapeutic progress can often be characterized by periods of growth, and plateau as the client moves through stages of their therapeutic process. Pivotal and meaningful moments are sometimes used to characterize phases of therapy and can represent aspects of the therapeutic relationship (Gavrielidou \& Odell-Miller, 2017). Significant moments in therapy occur when something new, different, pivotal, or especially meaningful happens and can be instrumental in client and therapist perspectives on the therapeutic process and relationship. Assigned significance and meaning of a moment in therapy is individual and unique to the therapist(s) and client(s) who were actively engaged in the therapeutic space together. Significant moments in therapy could be experienced as peak moments, moments of tension or sadness or anger, new insight, and/ or a shared inner connection between the therapist and client. They occur at different intervals or frequencies at various points in the therapeutic process. In work with individuals who communicate beyond words, these significant moments have also been described as the familiar connections and indicators that the relationship was well established and motivating for connection between the therapist and client (Lee, 2014; Swaney, 2020).

Therapists who work with individuals diagnosed with intellectual and developmental disabilities (I/DD) have described significant moments in therapy as familiar interactions that demonstrate stability in the therapeutic relationship, a new or unexpected occurrence during a session, a felt sense of the impact of an interaction, recognition and connection to another (Lee, 2014; Swaney, 2020). Some therapists have reported the extended length of time necessary for developing rapport and building relationships with clients (Lee, 2014). In these instances, familiarity was highlighted as a core tenet of the relationship and significant to therapeutic progress. The client consistently responding vocally to the therapist indicated the status of their significant relationship. Additionally, significant moments have been sometimes identified as when something new or unexpected happens within a session (Lee, 2014; Swaney, 2020). Unrehearsed, self-initiated musical contributions, and changes in body position, movement and facial expression, characterized interactions that were perceived by the therapist(s) as significant in the change that was highlighted from prior interactions. These moments were often reported to develop from structured musical interactions that created familiar connection points between the therapist and client.

Gavrielidou and Odell-Miller (2017) found that structured music and interventions were more likely to evoke pivotal and significant moments within sessions. These moments could happen while engaging with both pre-composed and improvised music. Engagement with music includes movement, active musical creation, receptive music listening, and singing pre-composed songs (Polen, 2013). Significant moments often launched clients into the next phases of their therapeutic process and impacted emotional processing. The accessibility of feeling and expressing emotional content in a nonverbal and contained environment is important for individuals who communicate 
most authentically using methods beyond words and may also be experiencing extreme emotional needs (Graham, 2004; Polen, 2013; Swaney, 2017; Swaney, 2020).

\section{Emotional Processing}

Although individuals diagnosed with I/DD may also have co-existing mental health needs, there is little existing literature exploring deeper aspects of the therapeutic process for clients diagnosed with I/DD, and even less for those who communicate primarily using methods beyond verbal language (Adams \& Oliver, 2011; Polen, 2013). Because of the perceived limits of processing emotional work with individuals who communicate beyond words, many counselors and other health professionals tend to avoid emotional processing within this population (Swaney, 2017). Although it has been supported that clients with "severe/profound" levels of I/DD experience emotion as deeply as a typically developing person, and can access music as a tool to process and express these feelings, there has still been debate over the abilities of individuals with I/DD diagnoses to express the same range of emotions as their typically developing peers (Adams \& Oliver, 2011; Graham, 2004; Lee, 2014; Polen, 2013; Swaney, 2017; Swaney, 2020). Music therapy can provide a unique outlet for nonverbal communication and self-expression, while the various information sources available to the music therapist can contribute to our knowledge and understanding of how moments in therapy impact the therapeutic process, and how clients express emotion through sound, movement, and affect (Dillard, 2006; Gavrielidou \& Odell-Miller, 2017; Graham, 2004; Polen, 2013; Stern, 2010; Swaney, 2017; Swaney, 2020).

\section{Communication and Information Sources}

Communication forms utilized in therapy by individuals diagnosed with I/DD can include, but are not limited to, reaching out, body orientation, facial expression, vocalizations, leading, eye gaze, gestures, head nods, Sign Language, pictures and icons, and voice output devices (Caldwell, 2013; Cascella \& McNamara, 2005; Graham, 2004). These communicative actions have functions that cover a wide range of intentions including to convey their emotions, make a choice, make requests, indicate dissent. In improvisatory contexts, a space is created which allows for additional communication through melody, dynamic, rhythm, and other musical elements.

Body movement and gesture can help add meaning and context to verbal dialogue and are also used as a primary form of communication for some individuals (Caldwell, 2013). Temporal elements found within movement patterns can offer additional insight into communicative intent and synchronicity between client and therapist within musical and nonmusical interactions (Foubert et al., 2017; Stern, 2010). Caldwell (2013) posited that body movement and behavior have an underlying meaning that could be uncovered through investigation of the environment and interactional patterns. "We have to empty ourselves of any behavioral expectations and learn to "be with' this person as they are at present, using their initiatives to respond in ways that have meaning for them" (p. 34). By experiencing full presence and openness to communication being transmitted from a variety of modalities, the therapist can gain a deeper understanding of a client's internal experience (Caldwell, 2013; Dillard, 2006; Scheiby, 2005; Seabrook, 2019; Stern, 2010; Swaney, 2017; Swaney, 2020). Characteristics of musical interactions, in body movement, rhythm, and melody, can offer snapshots of the therapeutic relationship at a given moment in time and demonstrate a client's growth over time (Caldwell, 2013; Foubert et al., 2017; Strehlow \& Linder, 2014; Swaney, 2017; Swaney, 2020).

Strehlow and Lindner (2014) identified interactional patterns present in improvisational interactions with clients diagnosed with borderline personality disorder (BPD). Scenes were chosen to represent different phases of treatment for the participants included in the study. Interactional patterns were identified and defined in terms of musical characteristics, relation to the therapist, therapist's feelings and inner thoughts, and the function of the music. Additionally, interpersonal temporal synchronicity be- 
tween the client and therapist has been used as a method of assessing an individual's ability to relate to another person (Foubert et al., 2017; Kleinlooh et al., 2021). Continued participation in successful interpersonal temporal synchronicity may have implications in improving temporal relational strategies as they impact attachment experiences. A large portion of therapeutic work with clients diagnosed with BPD is spent navigating the uncertainties of the client-therapist connection and finding balance between being over-involved or the client withdrawing and resisting the therapist. This is illustrated through the therapist's role and feelings highlighted in each interactional pattern and inconsistencies in temporal relation (Foubert et al., 2017; Kleinlooh et al., 2021; Strehlow \& Linder, 2014).

\section{Countertransference as an Information Source}

In addition to the musical contributions and body signs of emotional work, countertransference is a form of information about the improvisational interaction and how impactful or meaningful it may be in the therapeutic process. Joining in close proximity in musical exchange can bring forth countertransference, or an emotional reaction of the therapist to material brought into the therapeutic space by the client (Dillard, 2006; Scheiby, 2005). Countertransference can also serve as a tool for gaining insight into the client's perspective and underlying issues not revealed in verbal discussion.

Dillard (2006) interviewed music therapists regarding their experience of musical countertransference in individual music therapy. Music communicated client perceptions of their experience in the therapeutic process and highlighted interpersonal dynamics within the therapeutic relationship. In these interviews, countertransference was identified as a strong desire to respond that may or may not align with their conscious views. It also presented as an emotional or physical sensation, i.e., "jarred and out of control" or "chills, a "flipping over in my stomach"'(p. 213). Therapists who were interviewed acknowledged that countertransference, when consciously understood, was a useful tool for further interpreting and understanding their clients' experiences. Countertransference occurred with clients at significant points within the therapeutic process regardless of diagnosis.

\section{Summary}

Significant and pivotal moments in music therapy can be used to describe aspects of therapy, illustrate techniques, and inform clinical work and therapeutic progress for both the client and the therapist (Gavrielidou \& Odell-Miller, 2017). Environments with appropriate structure, autonomy and safety, similar to those that can be created within clinical improvisation, encourage these moments to occur and can propel the client forward in their progress and provide an outlet for emotional expression (Dillard, 2006; Gavrielidou \& Odell-Miller, 2017; Kenny, 2006; Polen, 2013; Seabrook, 2019; Scheiby, 2005; Strehlow \& Lindner, 2014). These moments are crucial and necessary for growth and change. Better understanding and identification could impact the direction of the therapeutic progress, relationship, and growth. As the therapist is better able to guide the client through these periods of growth and change, the client is better able to incorporate these changes and progress in their own process (Dillard, 2006; Gavrielidou \& Odell-Miller, 2017). Significant and pivotal moments as information sources could greatly contribute to the therapeutic process and relationship in the absence of verbal processing and communication between the therapist and client as is often the case in work with individuals diagnosed with I/DD.

Individuals who have experienced less access to emotional expression understood and accepted by mental health professionals can experience pivotal and meaningful moments in improvisation and could benefit from identification, validation, and processing of their emotions in therapy (Adams \& Oliver, 2011; Polen, 2013). Information gathered from sources beyond verbal dialogue (nonverbal communication, musical improvisation, and countertransference) could contribute to the understanding and deepening of therapeutic growth (Adams \& Oliver, 2011; Caldwell, 2013; Foubert et al., 
2017; Gavrielidou \& Odell-Miller, 2017; Lee, 2014; Polen, 2013; Strehlow \& Lindner, 2014; Swaney, 2017). Given these understandings and the limited amount of existing literature acknowledging the impact of the therapist's understanding and validating of emotional processing work within therapy with individuals diagnosed with I/DD, the purpose of this paper is to highlight specific significant moments within musical improvisations and their clinical implications.

The next four composite clinical excerpts are examples of significant moments in music therapy with individuals diagnosed with I/DD who have various communication methods and use music for self-expression. When sharing case examples of any kind, it is important to recognize and reflect on the fact that these are stories and moments in the lives of real people. While they can hold a great deal of weight and have the capacity to share knowledge that could benefit future clinicians and clients, these stories are often deeply personal and should be treated with great care and respect. Because of this fact, it is imperative to consider client preference and seek permission when hoping to share their stories with others. Permission for sharing their stories with others was gained in these instances directly from the clients involved in the creation of these composite cases.

Composite cases were selected in this instance as a method of further protecting the identities of clients involved, providing rich examples derived from work with multiple people, and offering input from a diverse range of people. Composite cases were created by combining aspects of different clients who had similar instances occur in their therapy and could bring together their similarities and unique features to create a cohesive case example. These excerpts demonstrate clinical work that is driven by a variety of information sources including musical elements, behavior, body movement, affect, verbal language, and therapist countertransference. Each excerpt is preceded by a description of the client and followed by a discussion of salient elements of each significant moment.

After each example is a discussion written in first person from the therapist's point of view about their experience and how it relates to the literature. The therapist included in this paper is also the author. To situate the therapist's narrative in these examples a short introduction is necessary.

I am a white, able-bodied, neurotypical, cisgender, heterosexual woman living and working in the southeast region of the United States. Through my parents' work as therapeutic foster care providers, during my childhood and adolescence, I have had multiple siblings with whom I have had very close relationships who were diagnosed with various disabilities. This experience and my experiences as a person with an anxiety disorder have greatly shaped the ways in which I perceive and respond to events and people. At the time of these excerpts, I was a fairly new music therapist at an Intermediate Care Facility (ICF) in an interdisciplinary team with four other creative arts therapists. I practice from a lens that is informed by the social model of disability, disability studies, and humanistic therapy (Cameron, 2014; Goodley, 2014; Hadley \& Thomas, 2018; Moore \& Lagasse, 2018; Rolvsjord, 2014). Advocacy for the needs and interests of clients and empowerment of individuals to engage actively with the direction of their therapeutic journeys is an important aspect of my practice. Clinical improvisation is incorporated into the majority of sessions, which has allowed for me to have increased authenticity in practice through being flexible, perceptive, and responsive in the moment.

\section{Case Examples}

\section{Countertransference as a Window Into Client Experience}

Kate was a young woman in her 30s who had an incredible relationship with music. She enjoyed a wide variety of music and expressed herself most readily through vocal and body improvisation. Kate would often participate in very long improvisations with the therapist, sometimes lasting 20-minutes or more. She sometimes engaged in self 
injurious behavior and used a helmet and arm splints to prevent injury 24-hours a day, with more restrictive restraints to use when her behaviors escalated. She communicated largely through body movement and affect. Kate used her time in music therapy to address needs in the areas of self-expression, self-awareness, and emotional regulation.

Kate was lying completely covered under her weighted blanket in the back room at her work site when I arrived. The staff said she had been upset earlier in the day and had gone to the back room to have some "quiet time." According to staff, Kate had been upset for much of the day and it was requested that I leave her alone if she was still upset. I told the staff that I would see how Kate was feeling and assess whether music therapy was appropriate for that time. Kate was very upset when I arrived in the room. She was vocalizing loudly "Mama," crying and engaging in occasional self-injurious behavior. Each time I tried to sing a song that I knew she was familiar with and had been meaningful for her in the past, she became more upset. As a final effort before leaving the room, I began an improvisation on the guitar using softly finger picked styles in E minor. At times when Kate was exhibiting stronger signs of distress (loud vocalizations, tears, tense body movement, erratic rhythmic motives), I simplified the music by reducing the number of strings I was using and plucking the low E string on the guitar in a slow and steady fashion. Once she calmed, I slowly increased the musical features of the improvisation to support her vocalizations and movement by adding melodic fragments and tonal features. After about 20 minutes of this procedure, I noticed a change in Kate's movement, increased steadiness of rhythmic rocking, and use of small percussion instruments, that indicated an openness to strummed patterns and vocal improvisation. I started a new chordal pattern moving back and forth between an E power chord and an A power chord with an added $9^{\text {th }}$. She looked up at me and I was immediately overcome with a calm sadness. I improvised a vocal melody over this chord progression using the words "It's okay to feel this way" allowing the final note of the phrase to jump into the upper range of my voice, almost as if it was cracking. Her gaze strengthened as she continued to look me directly in the eye. The sadness deepened as I added an additional phrase using power chords with added tension. Kate let out an "Ahhhhhh" vocalization that lasted for as long as her breath could sustain it. We continued this improvisation for several minutes. Next, I improvised a song about Kate's love, what I hoped it was for her and what I hoped it brought for her. She directly responded to my words in her music, actions, and affect. When I sang about her music, she vocalized and played the small percussion instruments even louder. When I sang about her smile, she turned to me and laughed. When it was time for me to leave the session, I felt very full and heavy and could not really place a label on the emotion I was feeling. My eyes were filling with tears of joy and thankfulness.

Kate was very clearly communicating her needs through her affect, body movement, and engagement in the session. I intuitively responded through words, music, and a supportive presence. The music was overall structured with repetitive melodic fragments and song form to allow Kate to explore and express her internal experience. This structure contributed to the predictability in the musical space essential to deeper emotional exploration (Gavrielidou \& Odell-Miller, 2017). Kate's various body movements could look similar whether they meant relaxed and content or tense and anxious, if the therapist had not also taken affect, speed, rhythmic consistency, and musical elements into account. Erratic body movement with tension in the body and affect led me to support by removing overwhelming stimuli until Kate communicated that she was open to additional tonal and melodic features. Rocking of the body in a steady and rhythmic fashion accompanied by a relaxed or bright affect would indicate that Kate was ready to engage with more diverse musical elements and that she may be feeling an increased level of connection to her body. Her vocalizations also used more open syllables as the session progressed and had a felt sense of release to them. During this excerpt, Kate modulated from the first type of movement to the second type because she was given the space and time to communicate her needs rather than having demands placed on her and interventions that she was expected to participate in (Caldwell, 2013). I was present in the moment and reacted according to Kate's communication and my own intuition and countertransference.

This excerpt provided very clear examples of countertransference. I felt sadness that was not my own and that I had not been feeling prior to that interaction. These feelings were sometimes indescribable and lasted into other parts of the day. Countertransfer- 
ence has been described as an uncontrollably strong and sometimes out-of-character reaction to a particular stimulus (Dillard, 2006). I was able to take this information and use it to inform my view of what Kate may have been experiencing during that session and provide future direction for our work together. Because Kate was so clearly impacted by processing her emotions through improvisation, I could ensure that space would be available in the future for this type of processing. Additionally, the staff witnessing this interaction and Kate's ability to safely process her emotions in ways she had been unable to earlier in the day, allowed for them to become an advocate for Kate to have access to music therapy when she was feeling upset rather than asking for Kate to be left alone.

\section{Shifts Found Within Patterns of Interactions}

Alisonwas a young woman in her 30s who had recently moved to a residential facility and self-identified improving her coping skills to be her goal for her time in music therapy. She had an extremely powerful voice and connected most to southern gospel and other Christian music. She typically refused participation in experiences using music that she was unfamiliar with. Alison indicated interest in working on a variety of musical projects including learning some guitar, recording and performing songs, writing her own music, and playing piano. Alison had a diagnosis of borderline personality disorder and became easily frustrated with these projects if they became challenging for her, and would often request to end early if she was not happy with the outcome of a project. Alison sometimes desired close connection with significant people in her life (her therapist and staff), and at other times Alison was distant and withdrawn from them. She had a history of violence towards others, threats of violence against herself, and destruction of property. Earlier in the week of this selected example, Alison had become aggressive towards support staff in her building and caused a great deal of property damage.

I arrived a few minutes early for our session and Alison was there waiting on me. I asked if she wanted me to hang out until it was time or if she wanted to start early. Alison was excited to get started and expressed that we should begin right away. Earlier in the day she had said she was feeling "crampy" and that she might not be able to do what we had planned to do during the session. I provided a choice of four different songs for us to use for expressive movement. Alison originally said she wanted to dance to the fastest one, but then when I played the song she said she did not like it and asked if I brought a country song for us to dance to. I told her that I didn't bring in songs because she would know them, but because I thought she would like to hear the message each song had. I told her the message of each song and asked that she choose what she needed to hear that day. She selected a song called 'Morning Prayer, I will surrender', which happened to be the slowest song I had brought that day. She chose to use rainbow ribbon streamers as a movement prop while I moved with a scarf. Alison began the movement experience with her body turned perpendicularly from mine. She then turned towards me and was moving her ribbon streamers very rapidly to the slowness of the music. I joined her in this rapid movement, intensified it while lifting my arms above my head, then suddenly sank into slow and flowing movements. Alison joined me and continued these slow movements in connection with me for the rest of the song. Her posture shifted so that she was facing me and she initiated bringing our movement props together or trading them several times throughout. The lyrics towards the end of the song were "I am kinder every moment every day, I am more loving ... . I will surrender to my highest greatest good." I sang out loud in the space between the words "I am kinder, I'm more loving, I'm trying my best." Alison joined me in singing and vocalizing in the space between the words until the music came to an end. I had goosebumps and a feeling of awe after the song ended. Alison stated that she too had goosebumps and identified the words "I'm trying my best" to be the most significant part of the experience.

Alison was initially unsure about participation in this experience that was outside of her familiar musical interactions. She was requesting faster music to move to and had traditionally used upbeat tempo as a method to escape her feelings and keep interactions in therapy on a surface level. When Alison began moving her ribbon streamers rapidly and in contrast to the music and myself, I joined her and she shifted, choosing 
to alter her movements to match the musical elements present. This shift allowed us to entrain our movements together into a period of temporal interpersonal synchronicity (Foubert et al., 2017; Stern, 2010). This is also supported by the characteristics of the initial musical interaction, which fell into the category of "music as a place of withdrawal" as evidenced by Alison's body posture and temporal disconnect from the music where she withdrew into an inner safety (Strehlow \& Linder, 2014). After the point of connection, Alison and I moved into a mixture of "music gives structure" and "music as a way of not being alone" where we fell back on the structure of the repetitive song and Alison initiated several connecting movements, such as trading props. The structure found in the repetitive form of the music and the safety of the strong therapeutic relationship allowed Alison to connect with the experience and further enabled the significant moment to occur (Gavrielidou \& Odell-Miller, 2017). The slight disruption in structure when certain words were emphasized by repeating them propelled us into a unifying affective response and accompanying realization of the impact of that moment (Dillard, 2006; Foubert et al., 2017; Kleinlooh et al., 2021; Scheiby, 2005). Alison confirmed that this moment was significant by identifying the disruption of structure as the most impactful portion of the session and expressing that she had received the message she needed from that interaction.

\section{Physical Safety to Allow Emotional Expression and Exploration}

Ethan was a 20-year-old man who began music therapy two weeks after being admitted to a residential facility from another group home. He was very energetic and seemed curious about his surroundings. Ethan enjoyed actively exploring the space and objects in the room. Ethan communicated primarily through grabbing objects and some gestures. His affect was sometimes blunted or inappropriate to other behavioral indicators of internal feeling state. Ethan had a history of property destruction, aggression, and self-injurious behavior. He also had a history of social isolation from a young age and spent much of his formative years alone. It was evident from the beginning that Ethan had a deep connection to music, was extremely interested in the guitar, and was motivated by a wide variety of musical styles. He often engaged in music by strumming the guitar, putting his hand inside the sound hole, drumming on the body of the guitar, moving his body, and vocalizing on a variety of syllables mostly in the extreme high range of his voice. His body movement was varied and he would sometimes rock his body back and forth, jump, spin, raise his arms above his head, and twist his head and neck in half circles from left to right.

Ethan was in his classroom and came to the door when I arrived. He seemed excited to see me and had a bright affect as he greeted me. I sang our typical greeting song while Ethan rocked his body and moved around the room. In an instant, his affect shifted and he very suddenly head butted me in the forehead. His one-on-one staff stood between us while I assessed myself. Ethan was sitting on the floor now and vocalizing repetitive higher pitched sounds. I tuned the guitar to DADGAD and moved into guitar improvisation to facilitate emotional expression. As I began changing the tuning, Ethan vocalized along with the pitches and stood up to pluck the strings. He pulled the strings towards himself forcefully, vocalized high pitched sounds and began moving around the room. Ethan walked around the room with instances of sudden jumps and other movements. I played a finger-picked style with sudden syncopated, loud and heavily strummed bar chords at the third and second frets. Ethan matched this with syncopated rhythmic drumming on the floor with his hand. I stomped my foot in response. Ethan again joined me in plucking the strings on the guitar and was focused on the higher pitched strings above the nut. This pattern of movement, guitar playing, and sitting on the floor continued and was joined by a "sssshhhhhhh" vocalization that I matched with my voice and by playing harmonics on the guitar. At times, Ethan walked away and then would come back when I added a melodic fragment in the higher range of the guitar. After about twenty minutes of improvisation I noticed that he had been sitting on the floor with his ears covered for longer than he had previously during the session. I tuned the guitar back to standard tuning and Ethan vocalized along with each pitch. I then sang a very light and soft blessing song and thanked Ethan for sharing his music. 
Ethan experienced a significant change in affect and musical elements from the beginning to the end of the excerpt above. At the beginning, Ethan was moving around the room at a faster rate and exhibiting more agitated movements, such as hitting the floor and syncopated jumps where the force was more directed at the floor. Ethan was quietly sitting on the floor, had increased his vocal range by lowering it over an octave, and congruently related to a slower finger-picked blessing song by the end of the session.

This interaction supported an idea mentioned in the literature that behavior, such as self-injurious behavior or aggression, may have a cause that is unable to be determined from the behavior itself (Caldwell, 2013). Just prior to him head butting me, something was triggered in Ethan that he needed to process. He was then given the space to be met musically, express his internal experience, and move into a calmer and safer state. Additionally, his behavior was not sought to be changed or diminished through the improvisation, but a space was provided for him to express his internal state in ways that were both authentic to him and safe for everyone in the room (Seabrook, 2019). It should be noted that the one-on-one support staff present in this session was essential to providing this baseline physical safety that allowed me to focus instead on creating a psychologically safe and responsive environment for Ethan to process his internal experience. There were times during the session when Ethan would begin to engage in movement that could potentially cause himself physical harm and the staff was quick and gentle with a response that allowed the movement to continue safely. As mentioned by Lee (2014), staff can provide a wealth of information and aid in ways that allow the therapist to focus on other areas knowing that a trusted partner is there when needed for further support.

\section{Grief Work Through the Purposes of Music}

Haroldwas a middle-aged man who had lived in institutional settings for most of his life and had a long-term history of involvement with various creative arts therapists. He communicated primarily through context, gestures, and a communication binder with reference pictures that he kept with him. Harold was diagnosed with anxiety in addition to intellectual disabilities, and his music therapy had primarily been relaxation-based using a vibroacoustic therapy bed for a few years. Harold's mother passed away suddenly, which led to a need for a new kind of processing that he had not engaged in previously with the therapist.

When Harold arrived in his session on the day he found out his mother had passed away, we held our session in the chapel at his request. Harold expressed that he would like for me to improvise on the piano as he listened. The first improvisation was my felt impression of how Harold was feeling. It was played in a minor mode with descending melodic and harmonic motion, moderately slow tempo and short repetitive phrases. After the music was finished, Harold silently turned his head towards me with tears in his eyes and began slowly nodding his head. Harold used gestures, newly created communication cards, and approximated words to communicate his preferences for a new improvisation. He requested that the next improvisation be fast, lower pitched, and represent feelings of being angry, nervous, and upset. I played in a locrian mode with a fast out-of-control sounding melodic figure in the left hand. There were loud bursts of added dissonance which were unpredictable and did not relate to other structural elements of the music. Harold again confirmed that both improvisations aligned with how he felt and immediately, unprompted, requested that the second improvisation be played again. As it was now towards the end of his session time, Harold and I came up with a gestural signal that he would use to direct the moment in the improvisation that the music would shift from an upset mood to sounds that represented his coping skills. When asked, he communicated that he needed the music to provide a space to feel the sadness.

Harold used a variety of communication methods pieced together to meaningfully dialogue about his internal feeling states and experience with the loss of his mother (Caldwell, 2013; Cascella, 2005). The music allowed Harold, who had some physical limitations that may have prevented him from creating music that accurately matched what he needed to express, to describe and then hear how he was feeling musically re- 
flected. Harold confirmed that he understood what purposes music had and used communication supports that we created together to advocate for his needs. Harold needed to feel the emotion more than he needed someone to direct him through a discussion of his coping skills and how to put this event in the past. It was important in this space that I emptied myself of expectations for what Harold needed and allowed myself to listen and work together with Harold to process the grief that accompanied the passing of his mother (Caldwell, 2013; Seabrook, 2019).

Harold had the ability to feel complex emotions and requested to use music to process and integrate these feelings (Polen, 2013). I assisted his ability to autonomously participate in this process by creating a communication method that allowed Harold to decide what function the music should play on that day and offering musical containment opportunities for him to feel heard and understood (Seabrook, 2019). While Harold directed a large portion of the course of this therapy, I supported and guided the process by suggesting exercises and creating outlets for him to share his grief in ways that could then be understood by other support staff without him having to rely on communication aids that were not sufficient to expressing his experience.

\section{Discussion}

These composite examples provided application of the various types of communication used within sessions and how to incorporate them into a multifaceted understanding of the session. Alison's typical method of communicating was through verbal language, but this often caused resistance and incongruent experiences in therapy when relying exclusively on verbal processing (Gavrielidou \& Odell-Miller, 2017). Through connecting with her body in movement, Alison found connection with the therapist and the music that enabled her to find meaning in the message she had requested to hear from the music. By observing to Alison's body positioning and the subtle changes in her movement patterns, the therapist gained a deeper understanding of what meaning the experience may have held. In the end, verbal processing proved to be unnecessary for Alison and the therapist following the movement improvisation. Harold combined many different forms of communication together to intricately address specific parts of the message he wished to share (Caldwell, 2013; Swaney, 2017). Harold had a working knowledge of the different resources available (gestures the therapist would recognize, picture cards available, words he could approximate, newly created communication cards, and song lyrics) and effortlessly moved between each method to generate discussion that led to musical processing of his grief. Ethan's and Kate's body movement, vocalizations, and musical characteristics provided additional insight into their processing needs and internal states (Caldwell, 2013; Graham, 2004). It also became evident that some behaviors, head-butting and self-injury, had an underlying cause that was not necessarily connected to the action itself (Caldwell, 2013; Swaney, 2017; Swaney, 2020).

In the institutional context where all of these individuals resided, these communications were frequently mis-labeled by professionals or missed altogether. Behaviors are often labeled without pause for reflection or consideration of context, which can lead to decisions and actions that do not actually support the needs being expressed by the individual (Caldwell, 2013; Swaney, 2017; Swaney, 2020). Movement and music, much like what is labeled as a "behavior" when working within the disability community, are external reflections of internal experiences. The two are both deeply connected to our bodies and internal rhythms, as our bodies are where our movement and music originate (Stern, 2010). By noticing shifts and changes in these external reflections, we are able to discover shifts happening internally and react appropriately to help provide safe spaces for authentic expression and processing.

Both Ethan and Kate had been discouraged from processing and expressing more difficult emotions by staff members because it was not understood how best to provide them the physical safety and tools to move through those spaces. Kate's staff, who knew her very well and had been working with her for many years longer than the 
therapist had, frequently discouraged the therapist from conducting sessions when Kate was upset despite previous experience demonstrating that music was a space in which Kate could safely express and move through tougher emotional spaces. When Kate's body movement patterns were accurately interpreted and supported, she was able to use them to communicate her needs and direct the musical support she received during the session. Ethan similarly used his body to direct the musical structure of the session by oscillating between more fluid movements and sudden bursts of syncopation within his body rhythms. His need for expression of the tension built within himself was met and supported musically, which allowed him to express and move through this emotional state and ultimate build rapport with the therapist.

Musical elements enabled the therapist to observe and interpret client response and engagement (Caldwell, 2013; Graham, 2004; Swaney, 2017; Swaney, 2020). Ethan responded to the guitar by matching pitch to the strings in his vocalizations and then experienced changes in both his temporal relation to music and the vocal range he used. His participation and connection to the music and the therapist was evident in his musical contributions (Swaney, 2020). Kate vocalized using first tense, closed syllables and then moved to long and open syllables that had a felt sense of release to them as the session progressed. Harold described musical elements that reflected his internal feeling state as a method of creating a space for him to feel and process his sadness (Polen, 2013).

Countertransference also played a role in each of these examples and impacted the therapist both during and after the session time. Countertransference can provide insight into the therapeutic relationship and the experience within the encounter when brought into conscious awareness and understood (Dillard, 2006). While this has not been frequently discussed in music therapy within this population, it is an experience that occurs regardless of diagnosis and perceived functioning level. It is important for music therapists to understand these reactions to their work and process these experiences so that they are consciously understood and the therapists can continue to serve clients with less risk of negative impacts of continuous and significant countertransference (Dillard, 6005; Scheiby, 2005).

People also experience shared moments of connection and understanding through movement and body communication (Dosamantes-Beaudry, 2007; Stern, 2010). Musically, various body movements and approaches shape the sounds created and provide insight regarding what experience or meaning is underneath the music. Physically, our motor system receives information from these experiences and is shaped by what we feel. Our interpretation of music, interactions, and experiences is frequently determined by our perception of the elements beyond the notes and rhythms and visible movements. This kinesthetic empathy can deepen our understanding of particular events within the therapeutic process and provide insight to possible future steps towards growth and development.

Within many areas of work that impact the disability community there are preconceived notions about what types of therapeutic growth and processing is achievable for people based on outside assessments of their abilities (Adams \& Oliver, 2011; Graham, 2004; Lee, 2014; Polen, 2013; Swaney, 2017; Swaney, 2020). This can create problematic situations for disabled individuals seeking therapeutic support services throughout many different stages of their lives. Using experiences and information gained from observation and learning through example, future clients can receive increased access to nonverbal emotional processing in therapy sessions. Bringing together the vast number of communication and informational resources available to therapists working within the disability community can weave a new network of understanding and advocacy for depth of therapeutic practice.

\section{Conclusion}

Improvisation can empower the client and bring the therapist and client into a space of mutual responsiveness. The client then brings material into this space in a way that is 
autonomous, authentic, and accepted. The therapist can respond empathically, relying on intuition and present awareness, to match and meet the implicit needs and requests in the client's offerings (Scheiby, 2005). This nonverbal method of self-expression allows for a greater ability to share thoughts, emotions, moments of connection, and more without the barriers and shortcomings of relying on verbal language. Because of this ability to interact, cultivate relationships, and participate in deep expression in a nonverbal manner, music therapy provides a unique space for clients to connect with and process emotional content using resources accessible to them beyond the limitations of words (Dillard, 2006; Graham, 2004; Polen, 2013; Swaney, 2017).

Communication and processing take many forms including movement, sound, silence, and others (Caldwell, 2013; Cascella, 2005; Graham, 2004; Swaney, 2017). Body based communication adds elements of embodied understanding and expression to otherwise primarily vision and sound-based strategies. Our rhythms and vibrations present in both visual and sound-based communications remain connected to our bodies and internal rhythms from which they originate (Stern, 2010). These realizations lead to our understanding that music and movement are inseparable from ourselves and are deeply connected to our bodies.

Significant and meaningful moments are present in work with adults diagnosed with I/DD and can serve as indicators of future therapy or achieved milestones (Gavrielidou \& Odell-Miller, 2017; Lee, 2014). By remaining open to, and accepting of, information from all possible sources, both easily identified and more subjective, therapists may be better able to serve clients and proceed in partnership by incorporating information provided using information sources beyond words (Adams \& Oliver, 2011; Caldwell, 2013; Gavrielidou \& Odell-Miller, 2017; Lee, 2014; Strehlow \& Lindner, 2014; Swaney, 2017). Deeper emotional work and support of emotional processing for adults diagnosed with I/DD could also be improved by therapists' understanding and acceptance of these information sources (Dillard, 2006; Scheiby, 2005). Additionally, advocacy for change within the everyday environment to accept and support communicative intent of the expressions of people diagnosed with I/DD may also increase the ability of clients to generalize relational growth to other areas of their lives (Swaney, 2020).

It is hoped that by bringing this information together and providing clinical examples that music therapists will consider their own clinical work and how these principles apply. Increased awareness of these ideas and how they connect to music therapy with adults diagnosed with I/DD and using various communication methods has the possibility to inspire and change the way clinicians practice and view their work in this population. With new tools and information sources available, there are new and unexpected opportunities for insight for both therapists and clients alike.

\section{Funding}

There was no funding for this project.

\section{About the Author}

Katelyn Beebe is a music therapist based in North Carolina, United States. She received a Bachelor of music performance and then went on to complete both the equivalency and Master of Music Therapy programs at Appalachian State University. Katelyn's research interests include extraverbal communication in therapy, improvisational music therapy, and empowerment of clients to participate actively in directing their therapeutic journeys.

\section{References}

Adams, D., \& Oliver, C. (2011). The expression and assessment of emotions and internal states in individuals with severe or profound intellectual disabilities. Clinical Psychology Review, 31, 293-306. http://doi.org/10.1016/j.cpr.2011.01.003

Bruscia, K. (2014). Defining music therapy (3rd ed.). University Park. 
Caldwell, P. (2013). Intensive interaction: Using body language to communicate. Journal on Developmental Disabilities, 19, 33-39.

Cameron, C. (2014). Does disability studies have anything to say to music therapy? And would music therapy listen if it did? Voices: A World Forum for Music Therapy, 14. Retrieved from https://voices.no/index.php/voices/article/view/2222/1976

Cameron, H. J. (2017). Long term music therapy for people with intellectual disabilities and the National Disability Insurance Scheme (NDIS). Australian Journal ofMusic Therapy, 28, $1-15$.

Cascella, P. W., \& McNamara, K. M. (2005). Empowering students with severe disabilities to actualize communication skills. TEACHING Exceptional Children, 37(3), 38-43. https://doi.org/10.1177/004005990503700306

Cooper, S., Smiley, E., Morrison, J., Williamson, A., \& Allan, L. (2007). Mental ill-health in adults with intellectual disabilities: Prevalence and associated factors. British Journal of Psychiatry, 190, 27-35. http://doi.org/10.1192/bjp.bp.106.022483

Dillard, L. (2006). Musical countertransference experiences of music therapists: A phenomenological study. The Arts in Psychotherapy, 33, 208-217. http://doi.org/10.1016/ j.aip.2006.01.002

Dosamantes-Beaudry, I. (2007). Somatic transference and countertransference in psychoanalytic intersubjective dance/movement therapy. American Journal of Dance Therapy, 29, 73-89. http://doi.org/10.1007/s10465-007-9035-6

Einfeld, S., Ellis, L., \& Emerson, E. (2011). Comorbidity of intellectual disability and mental disorder in children and adolescents: A systematic review. Journal of Intellectual and Developmental Disability, 36, 137-143. http://doi.org/10.1080/13668250.2011.572548

Foubert, K., Collins, T., \& Backer, J. (2017). Impaired maintenance of interpersonal synchronization in musical improvisations of patients with borderline personality disorder. Frontiers in Psychology, 8, 1-17. http://doi.org/10.3389/fpsyg.2017.00537

Gavrielidou, M., \& Odell-Miller, H. (2017). An investigation of pivotal moments in music therapy in adult mental health. The Arts in Psychotherapy, 52, 50-62. http://doi.org/ 10.1016/j.aip.2016.09.006

Goodley, D. (2014). Dis/ability studies: Theorising disablism and ableism. Routledge.

Graham, J. (2004). Communicating with the uncommunicative: Music therapy with pre-verbal adults. British Journal of Learning Disabilities, 32, 24-29. http://doi.org/10.1111/ j.1468-3156.2004.00247.x

Hadley, S., \& Thomas, N. (2018). Critical humanism in music therapy: Imagining the possibilities. Music Therapy Perspectives, 36, 168-173.

Kenny, C. (2006). Music and Life in the Field of Play: An Anthology. Barcelona Publishers.

Kleinlooh, S., Samaritter, R., van Rijn, R., Kulpers, G., \& Stubbe, J. (2021). Dance movement therapy for clients with a personality disorder: A systematic review and thematic synthesis. Frontiers in Psychology, 12, 1-12. http://doi.org/10.3389/fpsyg.2021.581578

Lee, J. (2014). A Phenomenological study of the interpersonal relationships between five music therapists and adults with profound intellectual and multiple disabilities. Qualitative Inquiries in Music Therapy, 943-86.

Moore, K., \& Lagasse, B. (2018). Parallels and divergence between neuroscience and humanism: Considerations for the music therapist. Music Therapy Perspectives, 36, 144-151. http://doi.org/10.1093/mtp/miy011

Polen, D. (2013). Severe to profound intellectual and developmental disabilities. In M. Hintz (Ed.), Guidelines for Music Therapy Practice in Developmental Care. Barcelona Publishers.

Rolvsjord, R. (2014). The competent client and the complexity of dis-ability. Voices: A World Forum for Music Therapy, 14. Retrieved from https://voices.no/index.php/voices/article/ view/2217/1971 
Scheiby, B. (2005). An intersubjective approach to music therapy: Identification and processing of musical countertransference in a music psychotherapeutic context. Music Therapy Perspectives, 23, 8-17. http://doi.org/10.1093/mtp/23.1.8

Seabrook, D. (2019). Toward a radical practice: A recuperative critique of improvisation in music therapy using intersectional feminist theory. The Arts in Psychotherapy, 63, 1-8. http://doi.org/10.1016/j.aip.2019.04.002

Stern, D. (2010). Forms of vitality: Exploring dynamic experience in psychology, the arts, psychotherapy, and development. Oxford University Press.

Strehlow, G. \& Lindner, R. (2014). Music therapy interaction patterns in relation to borderline personality disorder (BPD) patients. Nordic Journal of Music Therapy, 25, 134-158. http://doi.org/10.1080/08098131.2015.1011207

Swaney, M. (2017). Dialogue in the music: A music therapist's perspective on meaningful communication with people with severe and profound intellectual disability. Intellectual Disability Australia, 12-15.

Swaney, M. (2020). Four relational experiences in music therapy with adults with severe and profound intellectual disability. Music Therapy Perspectives, 38, 69-79. http://doi.org/ 10.1093/mtp/miz015 